\title{
Variation in body size and metamorphic traits of Iberian spadefoot toads over a short geographic distance
}

\author{
F. Marangoni \& M. Tejedo \\ Departamento de Biología Evolutiva, Estación Biológica de Doñana - CSIC, Sevilla, Spain
}

Keywords

amphibians; body size; geographic variation; metamorphosis.

\section{Correspondence}

Federico Marangoni. Current address: Centro de Ecología Aplicada del Litoral (CECOAL - CONICET), C.C. 291,3400 Corrientes, Argentina. Tel: 543783454418 ; Fax: 543783454421

Email: fmarangoni@ebd.csic.es

doi:10.1111/j.1469-7998.2007.00406.x

\begin{abstract}
Determinants of geographic variation in body size are often poorly understood, especially in organisms with complex life cycles. We examined patterns of adult body size and metamorphic traits variation in Iberian spadefoot toad (Pelobates cultripes) populations, which exhibit an extreme reduction in adult body size, $71.6 \%$ reduction in body mass, within just about $30 \mathrm{~km}$ at south-western Spain. We hypothesized that size at and time to metamorphosis would be predictive of the spatial pattern observed in adult body size. Larvae from eight populations were raised in a common garden experiment at two different larval densities that allow to differentiate whether population divergence was genetically based or was simply a reflection of environmental variation and, in addition, whether this population divergence was modulated by differing crowding larval environments. Larger adult size populations had higher larval growth rates, attaining larger sizes at metamorphosis, and exhibited higher survival than smaller-sized populations at both densities, although accentuated at a low larval density. These population differences appeared to be consistent once embryo size variation was controlled for, suggesting that this phenotypic divergence is not due to maternal effects. Our results suggest considerable genetic differentiation in metamorphic traits that parallels and may be a causal determinant of geographic variation in adult body size.
\end{abstract}

\section{Introduction}

Adaptive explanations for the evolution and maintenance of clinal variation in body size have been put forward, especially at large geographical scales, such as the Bergmann's rule and converse Bergmann's rule along latitudinal gradients (Ashton, 2002; Blanckenhorn \& Demont, 2004). However, two main difficulties arise in the analysis of the evolutionary significance of populational body size variation. First, the attribution of an adaptive origin to the observed size cline requires establishing the causal role of natural selection for current ecological conditions, whereas other causes such as drift, founder effects and inbreeding may remain as putative processes behind body size clines. It presents a problem especially in studies of long-range geographical clines, because distant and isolated populations may have arisen from independent phyletic evolution and thereby may compromise conclusions based on the current ecological conditions. One possibility to minimize the potential bias induced by such neutral historical processes is to analyse body size clines at short geographical scales (e.g. Skelly, 2004). Moreover, establishing the causal role of natural selection as a driver of observed body size clines necessitates establishing that the observed variation is due to genetic divergence, rather than due to direct environmental influences (e.g. phenotypic plasticity, Losos et al., 2000).
The second complexity in the analysis of the origin and evolution of the body size clines is that the mechanisms underlying the observed phenotypic variation are often unknown, especially in organisms with a complex life cycle and biphasic growth phases. In amphibians, differences in adult body size among populations are assumed to depend on the post-metamorphic pattern of growth and age at maturity (e.g. Halliday \& Verrell, 1988). However, because growth occurs both at the larval and at the juvenile stage, the dynamics of body size variation in amphibians is even more complicated to analyse and requires analysing the sources' variations that affect growth during both ontogenetic phases. Although larval growth represents scarcely $0.1-10 \%$ of the total growth until median adult size (Werner, 1986), age and size at metamorphosis may have strong effects on long-term fitness, such as age and size at first reproduction (Scott, 1994). For instance, stressful conditions operating during the larval stage, such as variation in larval density or food levels, may explain better the size and growth performance of terrestrial juveniles than do terrestrial conditions (e.g. Altwegg, 2003).

If a stressful environmental variation during the larval stage follows a geographical cline, and compensatory growth mechanisms do not work because of their costs (Metcalfe \& Monaghan, 2001), an observed geographical pattern in adult body size may simply reflect environmental 
variation occurring during the larval stage (Laugen et al., 2005). Therefore, among populations, the analysis of divergence in metamorphic size and the sources that may explain variation at this stage may be explicative of clinal variation in body size at maturity.

In this study, we investigated the patterns and causal sources of geographic variation in metamorphic traits along a steep geographic cline of adult body size in the Iberian spadefoot toad (Pelobates cultripes). We use an experimental common garden approach in conjunction with field surveys to control the multiple ecological factors that may influence phenotypic variation across populations (Trexler, Travis \& Trexler, 1990). We hypothesized that variation in metamorphic traits would be predictive of the spatial pattern observed in adult body size, and that this variation at the metamorphosis may be genetically driven. For this purpose, we examined: (1) the adult size and metamorphic traits clines; (2) the sources of microgeographic variation in body size at metamorphosis that allow us to differentiate whether population divergence is genetically based, or whether it is simply a reflection of environmental variation; (3) we discuss the possible correspondence and implications of the population divergence in metamorphic traits with the adult body size variation.

\section{Materials and methods}

\section{Populations and study site}

We examined the variation in body size and metamorphic traits of eight populations of P. cultripes distributed along a stretch of $120 \mathrm{~km}$ at south-western Spain encompassing two areas with different geological substrates: old hercinic granite-schist soils from Sierra Morena and sandy soils from quaternary aeolian deposits from Donana (Fig. 1). We selected three populations from the hercinic soils (Sierra, thereafter, Pedroso, Gerena and Aznalcollar, L1-L3, hereafter), and four populations from the sandy area (Donana, thereafter; Lazaro, Bodegones, Abalario and Reserva Biologica de Donana, S1-S4, hereafter). Finally, a geographically intermediate population (Sanlucar, $\mathrm{M}$, hereafter) was also selected (Fig. 1). All these populations breed in small and shallow temporary ponds that become flooded in the fall and dry up in the summer (Diaz-Paniagua, 1992). The main climatic variables did not differ considerably across the transect (annual average rainfall $=640$ and $585 \mathrm{~mm}$, temperature = July 25.7 and $24.51 \mathrm{C}$, January 9.6 and 10.61C, for L3 and S1 populations, respectively, DiazPaniagua, 1986).

\section{Adult study}

We collected mature individuals from seven out of eight populations, because for the $\mathrm{M}$ population adult body size information could not be obtained, from October 1999 to January 2004 (Fig. 1, Table 1). Breeding adult P. cultripes were sampled during chorusing nights between 20:00 and 2:00 h, either calling males or pairs in amplexus to ensure that all individuals were mature. Toads were separated by sex in independent plastic containers and brought to the laboratory. We measured: the snout-vent length (SVL) by placing each toad on a laminated graph paper

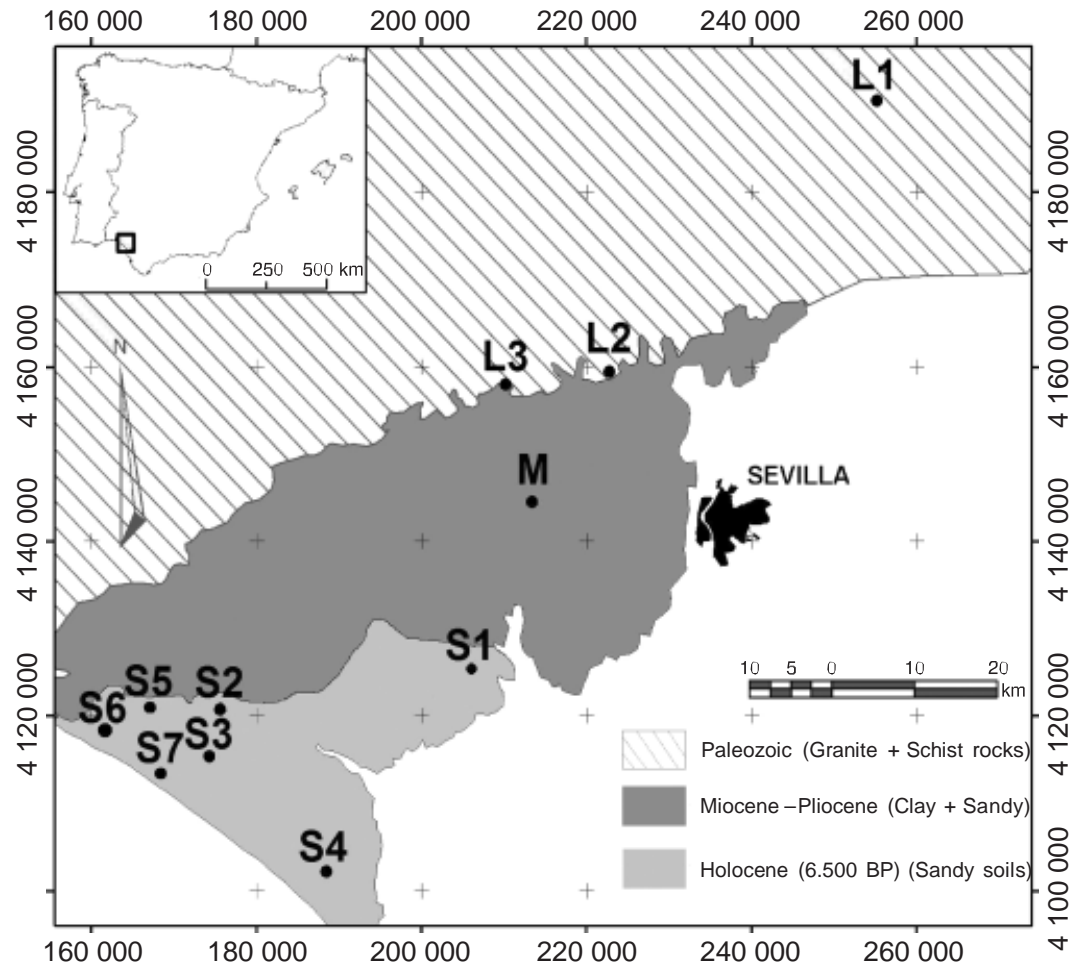

Figure 1 Map showing the location and geological substrate of the studied Pelobates cultripes populations. L1-L3, large adult body size populations; S1-S7, small adult body size populations; $M$, geographically intermediate population. 
Table 1 Descriptive information about the Pelobates cultripes study populations indicating number of adults sampled

\begin{tabular}{|c|c|c|c|c|c|c|}
\hline \multirow[b]{2}{*}{ Population } & \multirow[b]{2}{*}{ Abbreviation } & \multicolumn{2}{|l|}{ UTM $^{a}$} & \multirow[b]{2}{*}{ Elevation (m) } & \multicolumn{2}{|c|}{ Adults sampled } \\
\hline & & $x(m)$ & y (m) & & $\mathrm{M} / \mathrm{F}$ & All \\
\hline Pedroso & L1 & 255170 & 4190574 & 395 & $56 / 18$ & 74 \\
\hline Gerena & L2 & 222768 & 4159484 & 100 & 8/- & 8 \\
\hline Aznalcóllar & L3 & 210199 & 4158023 & 130 & $31 / 14$ & 45 \\
\hline Sanlúcar & M & 213349 & 4144548 & 34 & - & - \\
\hline Lázaro & S1 & 206339 & 4125928 & 20 & $18 / 1$ & 19 \\
\hline Bodegones & $\mathrm{S} 2$ & 175577 & 4120711 & 32 & $43 / 40$ & 83 \\
\hline Abalario & S3 & 174267 & 4115417 & 63 & $83 / 69$ & 152 \\
\hline RBD & S4 & 188450 & 4102197 & 24 & $47 / 24$ & $\begin{array}{c}71 \\
S=452\end{array}$ \\
\hline
\end{tabular}

${ }^{a}$ Coordinates UTM (Datum European 1950, Spain and Portugal, Zone: 30), elevation.

M, male; F, female.

(accuracy $\mathrm{T} 1 \mathrm{~mm}$ ), and body mass (BM) to the nearest $0.5 \mathrm{~g}$, using a $100 \mathrm{~g}$ Pesola spring balance (Pesola AG, Baar, Switzerland). Females' BM were only taken after oviposition, because we could possibly expect interpopulational differences in reproductive investment. Thus, gravid females were excluded from analyses. All individuals were released back into their original ponds (within $24 \mathrm{~h}$ after the capture).

\section{Larval common garden experiments}

We reared larvae from the eight sampled populations in two independent experiments (experiments I and II) in common garden mesocosms because not all the populations bred synchronously being unable to raise them in a single experiment.

\section{Experiment I}

On 7 November 2001, we sampled seven recently laid clutches of similar larval stage (Gosner stage 10, Gosner, 1960) belonging to four populations: three small adult size populations (S1, S3 and S4) and one large body size population (L2). A sample of around 500 eggs was carefully removed from each clutch and brought to the laboratory. Full-sib families were kept separately in plastic trays filled with dechlorinated tap water until tadpoles reached Gosner's stage 25 (Gosner, 1960). Room temperature was kept roughly constant (range 20-241C) and the photoperiod followed a natural cycle L10:D14.

Tadpoles from the four populations were reared in outdoor mesocosms in replicated octagonal artificial pools. A total of 12 plastic wading pools were set up in an outdoor facility at the 'La Hampa' field station (IRNA-CSIC). Pools were $2 \mathrm{~m}$ in diameter and $0.5 \mathrm{~m}$ in height and were previously filled with $500 \mathrm{~L}$ of well water on 27 November 2001. Pools were evenly distributed in a rectangular area, and two density treatments (low and high density) were alternatively assigned to each pool. To preserve population and fullsib information, tadpoles were reared individually (low density) or in groups of three (high density) in waste paper plastic baskets (height $=27 \mathrm{~cm}$, diameter $=21 \mathrm{~cm}$, full volume $=9 \mathrm{~L}$, filled volume $=7 \mathrm{~L}$ ) that were perforated
(2-3 mm grid) to allow the passage of water. The experimental densities were within the range observed in the natural ponds (Tejedo, 1993). The seven full-sib families from each population were included in the experiment to allow estimates of intrapopulation variation in metamorphic traits. The design thus corresponded with a splitplot design (Potvin, 1993) in which larval density was the main across-plot factor (with two levels, each replicated in six pools, fixed effect) and the population of origin was the subplot factor (fixed effect). The different pools were the plots (a random effect). Families were nested within populations and treated as a random factor. Each pool contained 56 baskets with two replicates per family per population, yielding a total of 12 replicates per family per density level. The experiment was started on 6 December 2001 when all larvae had reached a free feeding stage (Gosner stage 25).

\section{Experiment II}

Four additional P. cultripes populations were sampled on 14-17 November 2001 for a follow-up experiment: two with large adult body size populations (L1 and L3), one (S2) small adult body size and one (M) geographically intermediate. Only recently hatched tadpoles (25 Gosner stages) were collected, those likely belonging to different clutches, because tadpoles were collected from disparate parts of the ponds to maximize the chances of sampling unrelated animals, and with presumably similar ages (dates of reproduction on $5-8^{t}$ October). A total of either 240 (L1, L3, S2) or $110(\mathrm{M})$ tadpoles were dip-netted from each population, and kept outdoors in $45 \mathrm{~L}$ plastic containers filled with well water before the start of the experiments.

A total of 20 plastic pools $(1.5 \mathrm{~m}$ in diameter, $0.5 \mathrm{~m}$ in height) filled with $150 \mathrm{~L}$ of well water were used in this experiment. Pools were evenly distributed in a rectangular area next to experiment I, and the treatments (low density/ high density) were assigned to every second pool. In this experiment, each pool contained 21 baskets identical to those used in experiment I, holding either one (low density) or three tadpoles (high density). The design thus also corresponded with a split-plot design. Each pool contained 
six (L1, L3 and S2) or three (M) replicates per population. This experiment was started on 28 November 2001.

In both experiments, tadpoles were fed with $0.7 \mathrm{~g}$ of rabbit chow pellets twice a week. During the first month of the experiment, any dead tadpole was replaced and after this period, the survival of tadpoles was recorded every 15 days. The first metamorph (defined as the emergence of the first forelimb; Gosner stage 42) was found in both experiments on 21 April 2002. Metamorphs were brought to the laboratory and kept individually in $1 \mathrm{~L}$ plastic boxes at $22-241 \mathrm{C}$ until full tail resorption (around 8-9 days after forelimb protrusion, Gosner stage 46). The experiments lasted until 22 July 2002, the date on which the last metamorph was found in both experiments (after running 198 and 206 days in experiments I and II, respectively).

\section{Survey of size at metamorphosis in the wild}

During 2000 and 2004, 517 metamorphosing individuals were sampled from six natural populations to obtain an estimate of size at metamorphosis in the wild. Three of the sampled populations (L2, L3 and S2) were also analysed in the common garden experiments, and the other three (S5-S7, Fig. 1) came from the Doñana area. All metamorphosed tadpoles (Gosner stage 42) were brought to the laboratory and kept in plastic trays until completion of tail resorption. Metamorphs were weighed and measured following methods similar to those described above.

\section{Response variables and data analysis}

Larval common garden experiments were analysed in terms of survival, age and size at metamorphosis. Survival to metamorphosis was larval survival until the onset of metamorphosis (42 Gosner stage), at low density and the proportion of tadpoles that survived in each basket in the high-density treatment. Age at metamorphosis was the number of days elapsed between the beginning of the experiment and forelimb emergence, and the pools were checked every other day after the first metamorph appeared. Size at metamorphosis was measured as BM and SVL (mm) at complete tail resorption (Gosner stage 46). BM was measured to the nearest $0.1 \mathrm{mg}$ with an electronic balance (Mettler Toledo AG245, Mettler-Toleda GmbH, Greifensee, Switzerland). SVL was measured by placing each tadpole on a laminated graph paper (accuracy $\mathrm{T} 1 \mathrm{~mm}$ ). Growth rate was defined as ln (mass at metamorphosis)-ln (date of metamorphosis). To obtain an estimate of initial tadpole size in experiment I, 15 tadpoles from each family were photographed with a Digital Video Camera (JVC GR-DVX, JVC Yokohama, Japan) at the beginning of the experiment and tadpole size was estimated with an ImagePro Plus program (version 1.1 for Windows).

Baskets within pools were considered to be the experimental units in both experiments with individual response at low density and the mean of individual responses at high density. Adult BM, and mass and age at metamorphosis were ln transformed in order to meet the normality and homoscedasticity assumptions. Analyses of larval survival differed for both densities. At low densities, survival was analysed by fitting a binomial distribution of the data with a Logit Link function to yield maximum-likelihood ratio estimates using the Statistica 6.0 Visual GLZ Statistical Package (Statsoft, 2001). Survival at high larval densities was analysed by GLM after the proportion of individuals that reached metamorphosis was arcsine-square-root transformed to meet homogeneity of variances and normality. In experiment II, only BM at metamorphosis was analysed because we were not aware of the time that elapsed since tadpoles reached Gosner stage 25. In experiment I, initial tadpole size (for both densities) and larval survival (only for high density) were introduced as covariates in the analysis (ANCOVA) of the response variables (age and mass at metamorphosis, and growth rate). In experiment II, only survival for the high-density treatment was included as a covariate in the analysis. Means were compared using a post hoc Scheffe multiple comparison test, at $\mathrm{a}=0.05$. All statistical analyses were analysed with a type III general linear model using the Statistica 6.0 statistical package (StatSoft, 2001). All results are expressed as mean T 1 sE.

Field surveys and analyses of the variation in both adult body size and size at metamorphosis between source environments (Sierra-Doñana) and populations within environments were performed with nested ANOVAs.

\section{Results}

\section{Adult size}

A total of $\mathrm{N}=452$ adults of $\mathrm{P}$. cultripes were captured from seven populations (Table 1). The effect of source environment (Sierra-Doñana) was significant, BM: $\mathrm{F}_{1,384}=386.99$, PO0.0001; SVL: $F_{1,415}=360.03$, PO0.0001). We observed a reduction in the mean $\mathrm{BM}$ and SVL of adults from Sierra (L1-L3) to Doñana (S1-S4). The maximum observed reduction corresponded to $\mathrm{S} 1$, the smallest population within Doñana area (Fig. 2). This implied a reduction of $71.6 \%$ in $\mathrm{BM}$ and $36.8 \%$ in SVL with respect to the L3 population. In addition, there were significant effects of population within the environment (BM: $F_{3,384}=34.58$, PO0.0001; SVL: $\mathrm{F}_{3,415}=24.15$, PO0.0001).

\section{Common garden experiments}

\section{Experiment I}

The total length of tadpoles at the start of experiment I differed significantly among populations $\left(\mathrm{F}_{3,386}=10.99\right.$, PO0.001). Two groups were distinguished: the large body size population $(\mathrm{L} 2=1.11 \mathrm{~T} 0.02 \mathrm{~cm}, \mathrm{n}=105)$ had larger tadpoles than the three small body size populations $(\mathrm{S} 1=0.99$ T $0.02 \mathrm{~cm}, \mathrm{n}=105 ; \mathrm{S} 3=0.99 T 0.02 \mathrm{~cm}, \mathrm{n}=90$; $\mathrm{S} 4=0.98 \mathrm{~T} 0.02 \mathrm{~cm}, \mathrm{n}=90$; Scheffe range test, PO0.0001). There were also significant differences among families within populations $\left(\mathrm{F}_{22,364}=4.57\right.$, PO0.001), suggesting maternal and/or genetic effects in tadpole length. 

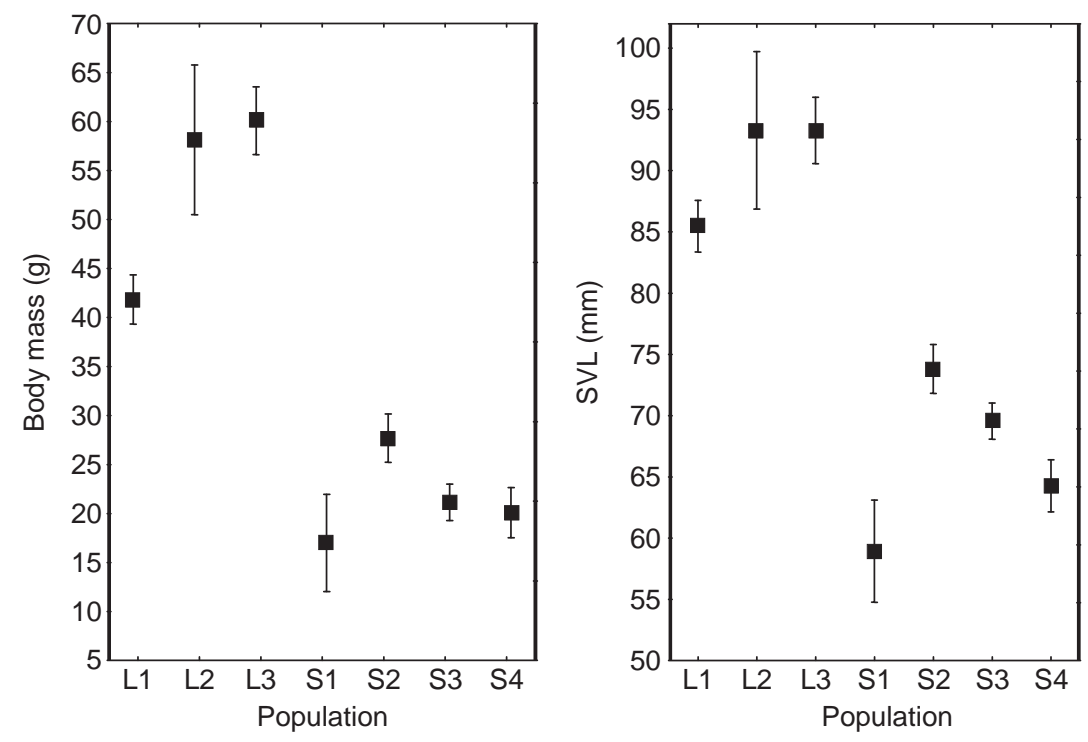

(a)

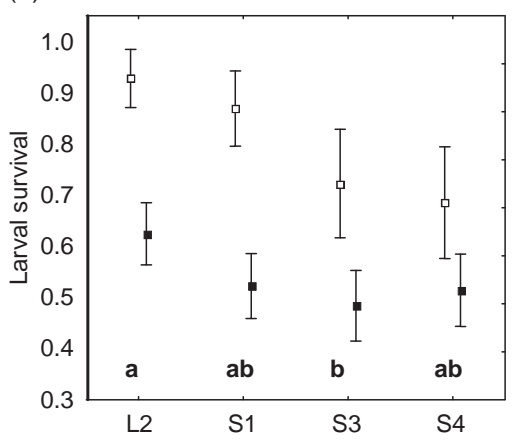

(c)

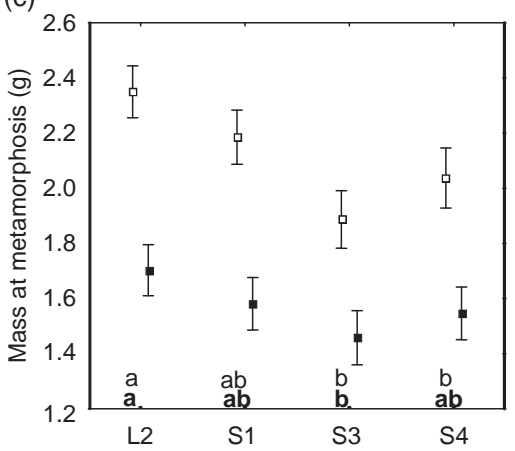

(b)

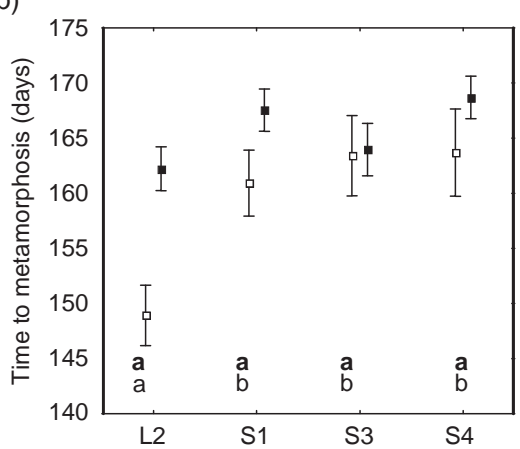

(d)

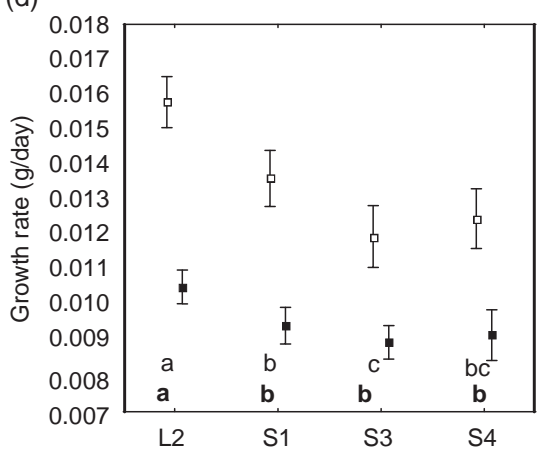

Figure 2 Variation in adult body mass and snout-vent length (SVL) across the study transect. The values represent means T $1 \mathrm{SE}$.
The populations differed significantly in mean survival at low density $\left(\mathrm{w}^{2}=22.05\right.$, d.f. $\left.=3, \mathrm{P}=0.00006\right)$. Survival was higher in large L2 than in two of the small body size populations (S3 and S4; Fig. 3a). At a high larval density, populations also differed $\left(\mathrm{F}_{3,303}=3.54, \mathrm{P}=0.015\right)$. The L2 population had higher survival than the S3 population (Scheffe test $\mathrm{P}=0.029$, Fig. 3a).

As revealed by the significant population $\times$ density interaction, age at metamorphosis differed among populations. These differences were accentuated at a low larval density (Table 2): where the L2 population reduced age at meta- morphosis by around $8.5-10 \%$ with respect to the small body size populations, this difference was only $4 \%$ at a high density (Fig. 3b). Population differences remained unaltered once initial tadpole size was included in the model as a covariate, suggesting that the differences were not caused by maternal effects that arise from variation in initial tadpole size (Table 2). At high densities, variation in larval survival did affect age at metamorphosis $\left(\mathrm{F}_{1,267}=13.31, \mathrm{P}=0.003\right)$ but the pattern of population divergence was not altered. There was also significant variation among families within populations in age to metamorphosis across densities 
(Table 3), suggesting genetic and/or maternal effects in developmental time.

L2 tadpoles were larger at metamorphosis than tadpoles from the small body size populations, although the differences were only significant for S3 and S4 (maximum difference between L2 and S3 was 20\% at a low density and 14\% at a high density, Fig. 3c). There was no significant population $\times$ density interaction indicating that reaction norms of different populations were parallel and the rank of populations did not change across densities. Either differences between populations did not shift once the initial larval size effect was controlled for (ANCOVA, Table 2). In the highdensity treatment, variation in larval survival affected size at metamorphosis $\left(\mathrm{F}_{1,263}=22.8\right.$, PO0.001), but the pattern of divergence among populations did not change.

The larval growth rate was significantly different among populations, being the highest for L2 tadpoles at both densities. The population $\times$ density interaction was not significant (Table 2). A Scheffe range test distinguished L2 clearly from the other populations, which showed a slower growth rate (Scheffe test Po0.05, Fig. 3d). Variation in larval survival at high density did not alter the pattern of population divergence in larval growth.

\section{Experiment II}

The populations included in experiment II showed a similar pattern of divergence in size at metamorphosis. Populations differed in size at metamorphosis $\left(\mathrm{F}_{3,362}=21.00\right.$, PO0.0001), and a significant population $\times$ density interaction $\left(\mathrm{F}_{3,362}=3.99, \mathrm{P}=0.008\right)$ arose because these differences were accentuated at a low larval density. At a low density, L3 metamorphs were $16.7 \%$ larger than S2 metamorphs, this difference being $11.9 \%$ at a high density (Scheffe test PO0.05, Fig. 4). This pattern of variation was not affected when variation in larval survival was controlled for (ANCOVA, P40.05).

\section{Field survey}

A total of $\mathrm{N}=517$ metamorphs of $\mathrm{P}$. cultripes were captured from six populations. The nested ANOVA revealed that size at metamorphosis in the natural ponds did not differ between source environments (Sierra-Doñana) $\left(\mathrm{F}_{1,499}=0.26, \mathrm{P}=0.63\right)$ and significant differences were found among populations within environments $\left(\mathrm{F}_{5,517}=\right.$ 150.28, PO0.001). For instance, L3 metamorphs were smaller than S2 and S7 metamorphs (Scheffe test, Po0.01, Fig. 5).

\section{Discussion}

\section{Population divergence in metamorphic traits, is it genetically based?}

Our results suggest that a significant portion of the observed variation among populations in the length of the larval period and in body size at metamorphosis is genetically 
Table 3 Results of two-way mixed model nested ANOVAs for responses of Pelobates cultripes populations to larval density accounting for variation among families in the experiment I

\begin{tabular}{|c|c|c|c|c|c|c|c|c|c|}
\hline & \multicolumn{3}{|c|}{ Age at metamorphosis } & \multicolumn{3}{|c|}{ Mass at metamorphosis } & \multicolumn{3}{|c|}{ Growth rate } \\
\hline & d.f. & MS & $\mathrm{F}$ & d.f. & MS & $\mathrm{F}$ & d.f. & MS & $\mathrm{F}$ \\
\hline Density & $1 / 9.90$ & $6219.4 / 2457.5$ & 2.53 & $1 / 10.40$ & $11.5 / 0.60$ & $19.05^{x x}$ & $1 / 10.20$ & $15.08 / 0.68$ & $22.31^{x \times x}$ \\
\hline Population & $3 / 22.51$ & $3067.5 / 107.7$ & $28.49^{x \times x}$ & $3 / 22.48$ & $0.78 / 0.07$ & $11.67^{x \times x}$ & $3 / 22.50$ & $1.37 / 0.07$ & $19.21^{x \times x}$ \\
\hline Density $\times$ population & $3 / 23.09$ & $745.5 / 50.8$ & $14.68^{x \times x}$ & $3 / 22.68$ & $0.011 / 0.05$ & 0.23 & $3 / 22.77$ & $0.07 / 0.05$ & 1.50 \\
\hline Pool (Den) & $10 / 465$ & $2556.3 / 65.6$ & $39.11^{\times \times \times}$ & $10 / 459$ & $0.62 / 0.04$ & $17.03^{x \times x}$ & $10 / 456$ & $0.69 / 0.04$ & $17.06^{x \times x}$ \\
\hline Families (Pob) & $22 / 22$ & $108.5 / 50.5$ & $2.15^{\times}$ & $22 / 22$ & $0.07 / 0.05$ & 1.41 & $22 / 22$ & $0.07 / 0.05$ & 1.54 \\
\hline Den $\times$ Families $(\mathrm{Pob})$ & $22 / 465$ & $50.5 / 65.6$ & 0.77 & $24 / 459$ & $0.05 / 0.04$ & 1.32 & $22 / 456$ & $0.05 / 0.04$ & 1.15 \\
\hline Error & 465 & 65.6 & & 459 & 0.04 & & 456 & 0.04 & \\
\hline
\end{tabular}

Response variable are age at metamorphosis, size at metamorphosis and growth rate. Significant values are highlighted in boldface.

${ }^{\mathrm{X} P 0} 0.05,{ }^{\mathrm{x}} \mathrm{P} 00.01,{ }^{\mathrm{x} \times \mathrm{P}} \mathrm{P} 0.001$.

d.f., degree of freedom numerator/degree of freedom denominator; MS, mean square numerator/mean square denominator.

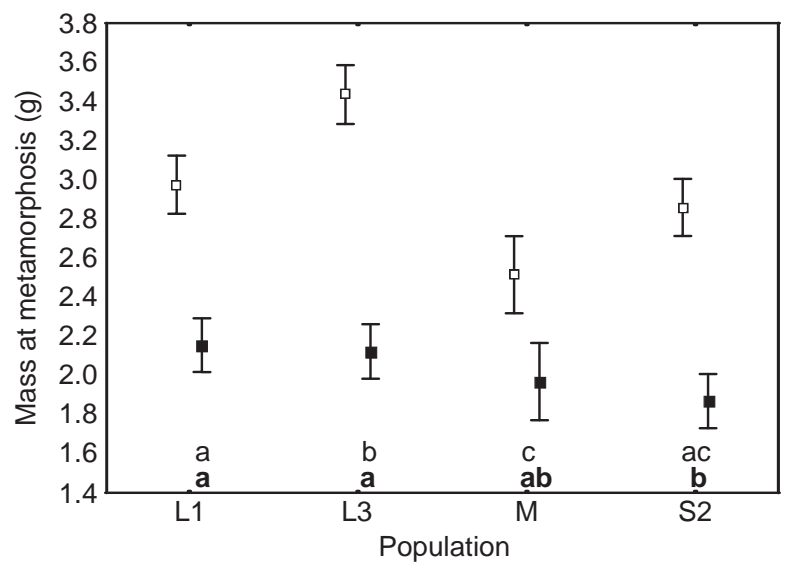

Figure 4 Variation in mass of Pelobates cultripes at metamorphosis in two density treatments (solid, high larval density; open, low larval density) for four populations in experiment II. The values represent means T 1 SE. Different letters indicate significant differences using a Scheffé post hoc multiple comparison test at a $=0.05$. Letters comparing high larval density treatment appear in bold.

based. In particular, large body size populations had faster developmental rates and were generally larger at metamorphosis than small body size populations. Moreover, geographic variation in metamorphic size obtained from common garden experiments paralleled the variation seen in adult body size. This last result contrasted with field surveys that indicated that not all large populations had a large size at metamorphosis. Large population L3 had a smaller metamorphic size than S2 and S7 populations whereas under controlled experimental conditions L3 had a larger metamorphic size than S2 at both experimental larval densities (Fig. 4). This was likely due to an extremely high larval density, and presumably high crowding conditions, found at L3 compared with the rest (M. Tejedo and F. Marangoni, pers. obs.). This contradictory result illustrates the need for an experimental approach in conjunction with field surveys to examine the problem of interdemic variation (Trexler et al., 1990).

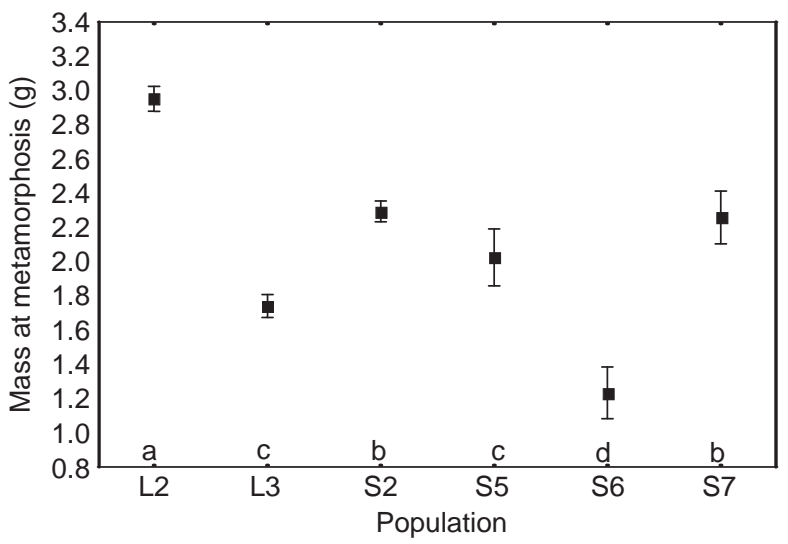

Figure 5 Variation in mass at metamorphosis in six Pelobates cultripes natural populations. The values represent means T $1 \mathrm{SE}$. Different letters indicate significant differences using a Scheffé post hoc multiple comparison test at $\mathrm{a}=0.05$.

The presumed genetic basis of observed geographic variation in metamorphic traits may be mingled with the interaction of maternal effects, which included environmental sources of variation. In amphibians, most variation in maternal effects is mediated through variations of egg size (Kaplan, 1998). For example, there is often a positive trend between propagule size and early life-history traits in amphibians and other organisms (Bernardo, 1996; Rasanen, Laurila \& Merila, 2005). Throughout the spadefoot toad populations studied, egg size displays a geographic variation parallel to that found in adult body size. Egg diameter was on average $11 \%$ greater in the large $\mathrm{L} 1$ population than in the small populations S2 and S3 (Marangoni, 2006). This variation could contribute to divergence in metamorphic traits between large and small body size populations if a larger egg size determines faster developmental and growth rates, and hence earlier onset of metamorphosis at larger sizes as it has been found in other species (Dziminski \& Roberts, 2006). Our results, however, did not sustain this argument because the pattern of divergence in metamorphic traits remained unaltered once variation in initial larval size 
was statistically controlled. Therefore, it is likely that the observed interdemic variation in metamorphic traits is mostly due to direct genetic effects rather than maternal effects arising from variation in propagule size.

The extent of population divergence in larval survival to metamorphosis will influence the rate of population recruitment of juveniles and thereby the dynamics of amphibian populations (Berven, 1990). In that sense, large body size populations would appear to have superior recruitment and thus higher fitness. Furthermore, juveniles from larger body size populations emerged $4-10 \%$ earlier than juveniles from smaller body size populations. Although these differences may appear to be of small magnitude, the actual divergence in days (over 2 weeks at a low density and a week at a high density) can potentially be highly biologically relevant because the biotic and abiotic conditions deteriorate dramatically as ponds approach desiccation (Wilbur, 1987). In addition, if larvae from larger body size populations reach metamorphosis both earlier and with a larger size, these populations would have an even greater fitness advantage by reaching larger juvenile size before aestivation in the dry and hot summer of Mediterranean environments.

The maintenance of the adult body size cline in P. cultripes appears to be contradictory in the light of our results. It seems rather paradoxical how genotypes from small size populations that express apparently maladaptive traits, lower larval survival, growth and developmental rates are maintained and not swept by better performance of genotypes from large adult size populations. In principle, gene flow can override population divergence under different selection pressures (Lenormand, 2002). Although we have no data on population genetic structure across the study transect for $\mathrm{P}$. cultripes, molecular results on another toad species Bufo (=Epidalea) calamita, which exhibits a parallel adult body size reduction, reveal that there is no pattern of isolation by distance through the study transect (Gomez-Mestre \& Tejedo, 2004, see also Marangoni, 2006). If we assume a similar pattern of no genetic isolation between large and small size populations in P. cultripes, the present pattern of population divergence in body size may be considered to be a consequence of local adaptation to differing selection pressures. If we take into account that other amphibian species exhibit a similar pattern of abrupt reduction in adult body size (Diaz-Paniagua, Mateo \& Andreu, 1996; Diaz-Paniagua \& Mateo, 1999), we may speculate that common selective pressures occurring at the Donana territory are conditioning a similar phenotypic outcome (Endler, 1977). Additionally, the pattern of population divergence may be simply the expression of environmental induction or phenotypic plasticity. Our results, based on reciprocal transplant experiments, between environments with large and small body size spadefoot toad populations, have revealed that terrestrial environments from small body size phenotypes yields lower growth rates when compared with environments with a large adult size (Marangoni, 2006). Therefore, this suggests that there may be variations in either the nutrient availability or other stressful factors that constrain the performance of growing terrestrial juveniles between the environments.

\section{Correspondence between the pattern of geographic variation in size at metamorphosis and the adult size}

In organisms with indeterminate growth, such as amphibians, differences among populations in body size of adults have been widely assumed to depend on variation in growth rates during the period from the post-metamorphic stage to sexual maturity (Halliday \& Verrell, 1988). The amount of size divergence at metamorphosis found between the large and small body size populations only accounted for c. $20 \%$ in BM. This divergence in metamorphic size comprises only a small fraction of the total size divergence found at adulthood, which is as most $71.6 \% \mathrm{BM}$ reduction, Fig. 2a). This suggests that additional differences have to be assessed between large and small body size populations during the post-metamorphic growth phase. Two alternative, although not mutually exclusive, mechanisms can account for population divergence during the post-metamorphic stage. First, larger body size populations may simply exhibit higher growth rates than smaller body size populations, and second, differences in the age of maturity and longevity between populations. Post-metamorphic growth in amphibians exhibits an indeterminate pattern with an exponential period that decreases considerably after the onset of reproduction with the attainment of an asymptotic size (Hemelaar, 1988). Thus, populations that delay reproduction are able to achieve larger body sizes than precocious ones (Morrison, Hero \& Browning, 2004). Data on post-metamorphic growth and demographic analysis of P. cultripes populations reveal that age structure and age at maturity do not differ between large and small body size populations, suggesting that the final pattern of body size divergence should be explained by differences in growth rates as suggested by our reciprocal transplant experiment (Marangoni, 2006).

In conclusion, our results suggest that the pattern of body size variation at the metamorphosis across the study transect is at least in part genetically determined and may be partially explicative of among-population variation in adult body size. However, mechanisms that operate through the post-metamorphic growth phase could contribute to the observed divergence in adult body size and need to be investigated further.

\section{Acknowledgments}

We thank F. Campos and L. Monzon for their assistance during the experiments. K. Rasanen, I. Gomez-Mestre, C. Franceschini and A.I. Kehr reviewed earlier drafts of this paper, providing useful comments that greatly improved the paper. Thanks are also due to the Consejerı de Medio Ambiente de la Junta de Andalucia and the Reserva Biologica de Donana, for providing the corresponding 
permits and facilities. All animal experimentation was conducted in accordance with the legal standards of Spain.

\section{References}

Altwegg, R. (2003). Multistage density dependence in an amphibian. Oecologia 136, 46-50.

Ashton, K.G. (2002). Do amphibians follow Bergmann's rule? Can. J. Zool. 80, 708-716.

Bernardo, J. (1996). The particular maternal effects of propagule size, especially egg size: patterns, models, quality of evidence and interpretations. Am. Zool. 36, 216-236.

Berven, K.A. (1990). Factors affecting population fluctuations in larval and adult stages of the wood frog (Rana sylvatica). Ecology 71, 1599-1608.

Blanckenhorn, W.U. \& Demont, M. (2004). Bergmann and converse Bergmann latitudinal clines in arthropods: two ends of a continuum? Integr. Comp. Biol. 44, 413-424.

Diaz-Paniagua, C. (1986). Reproductive period of amphibians in the biological reserve of Donana (SW Spain). In Studies in herpetology: 429-432. Rocek, Z. (Ed.). Prague: Charles University.

Diaz-Paniagua, C. (1992). Variability in timing of larval season in an amphibian community in SW Spain. Ecography 15, 267-272.

Diaz-Paniagua, C. \& Mateo, J.A. (1999). Geographic variation in body size and life-history traits in Bosca's newt (Triturus boscai). Herpetol. J. 9, 21-27.

Diaz-Paniagua, C., Mateo, J.A. \& Andreu, A.C. (1996). Age and size structure of population of small marbled newts (Triturus marmoratus pygmaeus) from Donana National Park (SW Spain). A case of dwarfism among dwarfs. J. Zool. (Lond.) 239, 83-92.

Dziminski, M.A. \& Roberts, J.D. (2006). Fitness consequences of variable maternal provisioning in quacking frogs (Crinia georgiana). J. Evol. Biol. 19, 144-155.

Endler, J.A. (1977). Geographic variation, speciation, and cline. Princeton: Princeton University Press.

Gomez-Mestre, I. \& Tejedo, M. (2004). Contrasting patterns of quantitative and neutral genetic variation in locally adapted populations of the natterjack toad Bufo calamita. Evolution 58, 2343-2352.

Gosner, K.L. (1960). A simplified table for staging anuran embryos and larvae with notes on identification. Herpetologica 16, 183-190.

Halliday, T.R. \& Verrell, P. (1988). Body size and age in amphibians and reptiles. J. Herpetol. 22, 253-265.

Hemelaar, A.S.M. (1988). Age, growth and other population characteristics of Bufo bufo from different latitudes and altitudes. J. Herpetol. 22, 369-388.
Kaplan, R.H. (1998). Maternal effects, developmental plasticity, and life history evolution. In Maternal effects as adaptations: 244-260. Mousseau, T.E. \& Fox, C.W. (Eds). Oxford: Oxford University Press.

Laugen, A.T., Laurila, A., Jonsson, K.I., Soderman, F. \& Merila, J. (2005). Do common frogs (Rana temporaria) follow Bergamann's rule? Evol. Ecol. Res. 7, 717-731.

Lenormand, T. (2002). Gene flow and the limits to natural selection. Trends Ecol. Evol. 17, 183-189.

Losos, J.B., Creer, D.A., Glossip, D., Goellner, R., Hampton, A., Roberts, G., Haskell, N., Taylor, P. \& Ettling, J. (2000). Evolutionary implications of phenotypic plasticity in the hindlimb of the lizard Anolis sagrei. Evolution 54, 301-305.

Marangoni, F. (2006). Variación clinal en el tamaño del cuerpo a escala microgeográfica en dos especies de anuros (Pelobates cultripes y Bufo calamita). PhD thesis, University of Seville, Spain.

Metcalfe, N.B. \& Monaghan, P. (2001). Compensation for a bad star: grow now, pay later. Trends Ecol. Evol. 16, 255-260.

Morrison, C., Hero, J.M. \& Browning, J. (2004). Altitudinal variation in the age at maturity longevity, and reproductive lifespan of anurans in subtropical Queensland. Herpetologica 60, 34-44.

Potvin, C. (1993). ANOVA: experiments in controlled environments. In Design and analysis of ecological experiments: 46-48. Scheiner, S.M. \& Gurevitch, J. (Eds). London: Chapman and Hall.

Rasanen, K., Laurila, A. \& Merila, J. (2005). Maternal investment in egg size: environment- and populationspecific effects on offspring performance. Oecologia 142, 546-553.

Scott, D.E. (1994). The effect of larval density on adult demographic traits in Ambystoma opacum. Ecology 75, 1383-1396.

Skelly, D.K. (2004). Microgeographic countergradient variation in the wood frog, Rana sylvatica. Evolution 58, 160-165.

StatSoft (2001). Statistica (data analysis software system),version 6. Tulsa: StatSoft.

Tejedo, M. (1993). Size-dependent vulnerability and behavioral responses of tadpoles of two anuran species to beetle larvae predators. Herpetologica 49, 287-294.

Trexler, J.C., Travis, J. \& Trexler, M. (1990). Phenotypic plasticity in the sailfin molly, Poecilia latipinna (Pisces:Poeciliidae). II. Laboratory experiment. Evolution 44, 157-167.

Werner, E. (1986). Amphibian metamorphosis: growth rate, predation risk, and the optimal size at transformation. Am. Nat. 128, 319-341.

Wilbur, H.M. (1987). Regulation of structure in complex systems: experimental temporary 15 pound communities. Ecology 68, 1437-1452. 